\begin{tabular}{ll} 
Abstract M2 Table 1 & \\
\hline Service offered & Response percent \\
\hline Chronic Disease Management & $95 \%$ \\
Home visits & $93 \%$ \\
Supported Discharge & $88 \%$ \\
Telephone Review & $86 \%$ \\
Admission Avoidance & $81 \%$ \\
Multi-Disciplinary Team meetings & $81 \%$ \\
Pulmonary Rehabilitation & $88 \%$ \\
Physiotherapy & $79 \%$ \\
Oxygen Assessment, Prescription and Review & $79 \%$ \\
Breathlessness Support & $75 \%$ \\
Anxiety Management & $77 \%$ \\
Palliative Care & $54 \%$ \\
End of Life Care & $54 \%$ \\
Spirometry & $88 \%$ \\
Case Finding & $25 \%$ \\
Diagnostics & $15 \%$ \\
Smoking Cessation & $52 \%$ \\
Management of Co-morbidities & $61 \%$ \\
Medicines Reviews & $65 \%$ \\
Intravenous Medication Services & $6 \%$ \\
Diet and Nutritional Support & $36 \%$ \\
Occupational Therapy & $15 \%$ \\
Speech and Language Therapy & $6 \%$ \\
Multi-professional Clinics & $52 \%$ \\
Virtual Clinics & $34 \%$ \\
Education of Generalists & $68 \%$ \\
\hline
\end{tabular}

\section{M3 EFFECT OF A 'DEFER DISPENSING INHALED THERAPY' PROGRAMME IN AN ACUTE HOSPITAL TRUST}

J Clark, D Eaton, I Congleton. Royal Sussex County Hospital, Brighton, UK

\subsection{6/thoraxjnl-2017-210983.425}

Methods Our acute hospital's spend on inhaled therapy is high, and was rising year on year. It is recognised that 'stockpiling' of inhaled therapy occurs, and that patients often don't bring in their inhalers when admitted acutely. In October 2016 we drew up guidelines for our hospital pharmacists aiming to support them in safely deferring dispensing inhalers, allowing time for patients to arrange for inhalers to be brought in from home. We developed a flow chart, with posters displayed on the medical wards as reminders. In addition we encouraged pharmacists not to dispense a new type of inhaler unless the patient had been assessed as able to use it by the Respiratory Nurse Specialist. From April 2016 we also started actively changing patients from high cost to lower cost devices, matching the local CCG prescribing incentive scheme for 2016-2017.

Results Following the 'Defer Dispensing' programme there was a $28 \%$ reduction in spend on inhaled therapy and a $6.5 \%$ reduction in the number of items dispensed, (See Table). Using 2016-2017 figures the average cost of inhalers dispensed was $£ 14.21$, giving a saving of $£ 10757$ related to reduced number of items dispensed. In the first 3 months of this year (20172018 ) there has been an additional 23\% cost reduction compared to previous year's equivalent time period and a $5.2 \%$ reduction in number of items dispensed.
Conclusion There is scope to impact on respiratory pharmacy spend in acute trusts. This was achieved both by swapping to lower cost preparations, with ongoing benefit to the local health economy, plus a reduction in the number of items dispensed. We believe that there is potential for further savings by making dispensing of inhaled therapy a more robust process.

\begin{tabular}{|c|c|c|c|c|}
\hline $\begin{array}{l}\text { Financial } \\
\text { year }\end{array}$ & $\begin{array}{l}\text { Spend on } \\
\text { inhaled therapy }\end{array}$ & $\begin{array}{l}\text { Change from } \\
\text { previous year }\end{array}$ & $\begin{array}{l}\text { Number of items } \\
\text { dispensed }\end{array}$ & $\begin{array}{l}\text { Change from } \\
\text { previous year }\end{array}$ \\
\hline $\begin{array}{l}2014- \\
2015\end{array}$ & f1 91460 & & 11233 & \\
\hline $\begin{array}{l}2015- \\
2016\end{array}$ & f1 98624 & $+f 7164$ & 11671 & +438 \\
\hline $\begin{array}{l}2016- \\
2017\end{array}$ & f1 55123 & -f43 501 & 10914 & -757 \\
\hline
\end{tabular}

\section{M4 MEETING THE PSYCHOLOGICAL NEEDS OF COPD PATIENTS AND ENHANCING SELF-EFFICACY: INTEGRATING CLINICAL PSYCHOLOGY IN A COMMUNITY RESPIRATORY SERVICE}

CSJ Chan, L Graham, D Roots, M Hodson, S Sunak. Homerton University Hospital NHS Foundation Trust, London, UK

\subsection{6/thoraxjnl-2017-210983.426}

Introduction and Objectives An average of $40 \%$ of Chronic Obstructive Pulmonary Disease (COPD) patients suffer from clinical depression and anxiety disorders, at least twice as much as reported by the general population. In COPD patients, comorbid mental health problems significantly predict more frequent symptom exacerbation, inpatient admissions, poorer functional status and quality of life due to reduced self-care. Typically up to $50 \%$ of treated COPD patients reported improvements of depression and anxiety symptoms after psychological therapy. However, conventional mental health services (e.g., Improving Access to Psychological Therapies services) have experienced challenges in engaging, assessing, and treating this patient group. The current study explores the clinical outcomes of a psychology service integrated into the existing COPD management frameworks and pulmonary rehabilitation programs in the London Borough of City and Hackney; in particular its impact on patients' access to psychological therapy, changes in mental health symptoms, quality of life and patient experiences of COPD.

Methods Self-reported experience of mental health symptoms was measured by the Hospital Anxiety and Depression Scale (HADS). Changes in patient experiences' including their perceived control and adjustment pre- and post-psychological interventions was measured by the COPD Patients-reported Experience Measure (COPD-PREM9).

Results In the 12 months between April 2016 and March 2017, the integrated psychology service received referral for 122 and offered interventions for 108 COPD patients, a significant improvement from that reported by the local IAPT service. 52 out of 108 patients who completed treatment required home-based psychological interventions due to their physical needs and were unsuitable for IAPT services. 44\% reported a significant improvement in their symptoms of 